\title{
SISTEMUL DE CLASIFICARE A FUNCȚIEI MOTORII GROSIERE ŞI SISTEMUL DE CLASIFICARE A ABILITĂṬII MANUALE ÎN EVALUAREA PARALIZIEI CEREBRALE
}

\author{
Ioana Grigore, Georgeta Diaconu, Cătălin Prazaru, Alexandra Mania, Ana Ulinici \\ Clinica de Neurologie Pediatrică, \\ Spitalul Clinic de Urgență pentru Copii ,Sfânta Maria“, Iaşi
}

\begin{abstract}
REZUMAT
Paralizia cerebrală (PC) este o boală cerebrală cronică, definită ca un grup de afecțiuni motorii neprogresive care debutează în primul an de viață şi care sunt secundare leziunilor survenite la un creier aflat în dezvoltare. La vârsta pediatrică este principala cauză a tulburărilor motorii severe şi invalidante.

Obiectivul lucrării. Încadrarea comparativă în diverse grade de severitate a PC la copil aplicând cele două clasificări: Sistemul de Clasificare a Funcției Motorii Grosiere (Gross Motor Function Classification System GMFCS) şi Sistemul de Clasificare a Abilității Manuale (Manual Ability Classification System - MACS).

Material şi metodă. Grupul de studiu a cuprins 129 de copii (43 de fete şi 86 de băieți), cu vârste cuprinse între 2-18 ani, diagnosticați cu diferite forme de PC. Protocolul de studiu a inclus examen clinic general şi examen neurologic. Rezultate. Dintre pacienții cu PC urmăriți, 24 (18,60\%) au fost încadrați la gradul I atât în clasificarea GMFCS, cât şi în MACS. De asemenea, dintre cei 69 de copii care puteau merge independent (GMFCS I+II), 60 aveau dexteritate manuală bună sau foarte bună (MACS I+II). În formele severe de PC (GMFCS V), 32/35 bolnavi nu puteau mânui obiectele fiind încadrați în MACS $\vee$ şi 3 puteau manipula numai anumite obiecte, fiind incluşi în MACS IV.

Concluzii. Funcția motorie grosieră şi abilitatea manuală evoluează pe paliere diferite de gravitate în funcție de tipul PC. În PC diskinetică, ataxică şi mixtă, s-a remarcat o mai mare corespondență între gradele de severitate conturate de cele două clasificări.
\end{abstract}

Cuvinte cheie: paralizie cerebrală, funcție motorie, abilitate manuală, copil

Paralizia cerebrală este o boală cerebrală cronică, definită ca un grup de afecțiuni motorii neprogresive care debutează în primul an de viață şi care sunt secundare leziunilor survenite la un creier aflat în dezvoltare.

Paralizia cerebrală $(\mathrm{PC})$ reprezintă la copil o problemă importantă de sănătate, numeroase studii raportând o rată a prevalenței de $1-2,4$ cazuri/ 1.000 de nou-născuți (1). La vârsta pediatrică este principala cauză a tulburărilor motorii severe şi invalidante.

Scopul acestui studiu a fost încadrarea comparativă în diverse grade de severitate a PC la copil aplicând cele două clasificări: Sistemul de Clasificare a Funcției Motorii Grosiere - Gross Motor Function Classification System (GMFCS) şi Sistemul de Clasificare a Abilității Manuale - Manual Ability Classification System (MACS).

\section{MATERIAL ŞI METODĂ}

Grupul de studiu a cuprins 129 de copii (43 de fete şi 86 de băieţi) cu vârste cuprinse între 2-18 ani, diagnosticați cu diferite forme de paralizie cerebrală în Secția de Neurologie Pediatrică a Spitalului Clinic de Urgență pentru Copii „Sf. Maria“, Iaşi, în perioada 2007-2013. Toți părinții au semnat consimțământul informat. Clasificarea PC s-a făcut în conformitate cu propunerea Surveillance of Cerebral Palsy in Europe Group din 2000 (2). Dintre copiii studiați, $114(89,37 \%)$ au fost diagnosticați cu forme spastice de PC, $8(6,2 \%)$ cu PC diskinetică, $5(3,87 \%)$ cu PC ataxică şi $2(0,56 \%)$ cu PC mixtă. Dintre cei 114 pacienți încadrați în PC spastică, $73(64,03 \%)$ au îndeplinit criteriile pentru diagnostic pentru PC spastică bilaterală (39 de copii cu diplegie spastică, 34 de copii cu tetraplegie spastică) şi $41(35,97 \%)$ pentru PC spastică unilaterală (37 de copii cu hemiplegie, 4 copii cu monoplegie).

Protocolul de studiu a cuprins examen clinic general şi examen neurologic. Pentru descrierea funcției motorii la copiii cu PC s-a utilizat Gross Motor Function Classification System descrisă de Palisano (3) în 1997 şi Manual Ability Classification 
System descrisă de Eliasson (4) în 2006. Cu ajutorul GMFCS s-a evaluat, pentru fiecare pacient în parte, prezența, amplitudinea şi forța mişcărilor active, în special a mersului, în gradul I fiind încadrați pacienții la care mişcările active se realizează fără restricții importante, în timp ce la gradul $\mathrm{V}$ au fost incluşi copiii care nu au capacitate de deplasare, fiind complet imobilizaţi (Tabelul 1). $\mathrm{Cu}$ ajutorul MACS s-a evaluat modul în care copiii cu PC cuprinşi în studiu îşi utilizează membrele superioare pentru a manipula diverse obiecte în activităţi cotidiene. În cadrul MACS grad I au fost cuprinşi pacienții cu o bună abilitate manuală, iar la gradul V copiii care nu prezintă nici o funcție manuală activă (Tabelul 1).

TABELUL 1. Criteriile de clasificare pentru Gross Motor Function Classification System (Palisano, 1997) şi Manual Ability Classification System (Eliasson, 2006)

\begin{tabular}{|l|l|}
\hline GMFCS & MACS \\
\hline $\begin{array}{l}\text { GMFCS I } \\
\text { mers independent, fără } \\
\text { restricții, dar există } \\
\text { dificultăți în mişcările } \\
\text { grosiere mai avansate }\end{array}$ & $\begin{array}{l}\text { MACS I } \\
\text { manipulează obiectele uşor, } \\
\text { corect şi cu succes }\end{array}$ \\
\hline $\begin{array}{l}\text { GMFCS II } \\
\text { mers independent, dar cu } \\
\text { restricționarea activităților } \\
\text { în exterior }\end{array}$ & $\begin{array}{l}\text { MACS II } \\
\text { poate manipula majoritatea } \\
\text { obiectelor, dar există o oarecare } \\
\text { reducere calitativă a prinderii sau } \\
\text { a vitezei acesteia }\end{array}$ \\
\hline $\begin{array}{l}\text { GMFCS III } \\
\text { mers posibil cu sprijin, cu } \\
\text { restricționarea activităților } \\
\text { în exterior }\end{array}$ & $\begin{array}{l}\text { MACS III } \\
\text { manipulează cu dificultate } \\
\text { obiectele, are nevoie de ajutor } \\
\text { în pregătirea sau modificarea } \\
\text { activităților }\end{array}$ \\
\hline $\begin{array}{l}\text { GMFCS IV } \\
\text { mers imposibil, limitarea } \\
\text { mobilității globale }\end{array}$ & $\begin{array}{l}\text { MACS IV } \\
\text { poate manipula numai anumite } \\
\text { obiecte care sunt uşor de mânuit } \\
\text { şi numai în anumite situații }\end{array}$ \\
\hline $\begin{array}{l}\text { GMFCS V } \\
\text { mers imposibil cu limitarea } \\
\text { globale }\end{array}$ & $\begin{array}{l}\text { MACS V } \\
\text { nu poate manipula obiecte şi are } \\
\text { abilități limitate chiar în realizarea } \\
\text { acțiunilor simple }\end{array}$ \\
\hline gMFsanobilităii
\end{tabular}

GMFCS = Gross Motor Function Classification System,

MACS = Manual Ability Classification System.

\section{REZULTATE}

Pentru fiecare copil cu PC s-a determinat la aceeaşi vârstă atât gradul GMFCS, cât şi MACS şi s-a încercat stabilirea unei corelații între nivelul dexterității manuale şi nivelul funcției motorii grosiere. Dintre pacienții cu PC urmăriți, 24 (18,60\%) au fost încadrați la gradul I atât în clasificarea GMFCS, cât şi în MACS. De asemenea, dintre cei 69 de copii care puteau merge independent (GMFCS I+II), 60 aveau dexteritate manuală bună sau foarte bună (MACS I+II). Dintre cei 35 de pacienți cu forme severe de PC (GMFCS V), 32 nu puteau mânui obiectele fiind încadraţi în MACS V şi 3 puteau manipula numai anumite obiecte, fiind incluşi în MACS IV (Tabelul 2).

Tabelul 2. Corelația între Gross Motor Function Classification System şi Manual Ability Classification System la copiii cu paralizie cerebrală

\begin{tabular}{|c|c|c|c|c|c|}
\hline \multirow{2}{*}{ GMFCS } & \multicolumn{5}{|c|}{ MACS } \\
\cline { 2 - 6 } & Nivel I & Nivel II & Nivel III & Nivel IV & Nivel V \\
\hline \multirow{2}{*}{ Nivel I } & $\begin{array}{c}24 \\
(18,58 \%)\end{array}$ & $\begin{array}{c}13 \\
(10,10 \%)\end{array}$ & $1(0,78 \%)$ & - & - \\
\hline \multirow{2}{*}{ Nivel II } & $\begin{array}{c}8 \\
(6,20 \%)\end{array}$ & $\begin{array}{c}15 \\
(11,63 \%)\end{array}$ & $8(6,20 \%)$ & - & - \\
\hline \multirow{2}{*}{ Nivel III } & $\begin{array}{c}3 \\
(2,33 \%)\end{array}$ & $\begin{array}{c}2 \\
(1,55 \%)\end{array}$ & $2(1,55 \%)$ & $\begin{array}{c}2 \\
(1,55 \%)\end{array}$ & - \\
\hline \multirow{2}{*}{ Nivel IV } & $\begin{array}{c}2 \\
(1,55 \%)\end{array}$ & $\begin{array}{c}3 \\
(2,33 \%)\end{array}$ & $3(2,33 \%)$ & $\begin{array}{c}6 \\
(4,64 \%)\end{array}$ & $\begin{array}{c}2 \\
(1,55 \%)\end{array}$ \\
\hline Nivel V & - & - & - & $\begin{array}{c}3 \\
(2,33 \%)\end{array}$ & $\begin{array}{c}32 \\
(24,8 \%)\end{array}$ \\
\hline
\end{tabular}

GMFCS = Gross Motor Function Classification System, MACS = Manual Ability Classification System .

De asemenea, s-a încercat realizarea unei corelații între forma de paralizie cerebrală şi clasificările GMFCS şi MACS (Tabelul 3).

\section{DISCUȚII}

Determinarea şi evaluarea periodică a funcției neuromusculare la copiii cu PC sunt esențiale pentru stabilirea planului de recuperare neuromotorie (5). În prezent există numeroase metode de evaluare a funcției motorii grosiere, a mersului şi a abilităţii manuale la aceşti pacienți. Gross Motor Function Classification System este valoroasă în evaluarea clinică a copiilor cu PC, reprezentând o scală fidelă de apreciere a severității deficitului motor (5). De asemenea, Manual Ability Classification System constituie o metodă important de apreciere a gradului de utilizare a membrelor superioare deoarece în PC funcția motorie grosieră şi abilitatea manuală nu sunt echivalente. Funcția membrului superior depinde în mare măsură de abilităţile cognitive şi de controlul voluntar motor, existând frecvent diferențe semnificative între capacitatea maximă şi performanța spontană, între ceea ce copilul poate să facă şi ceea ce vrea să facă (6).

În studiul nostru, la toți pacienții cu monoplegie deficitul motor interesa un membru inferior, fiind încadrați în GMFCS grad I, iar capacitatea de utilizare a membrelor superioare nu era afectată. La copiii cu hemiplegie spastică s-a observat că abilitatea manuală era mai afectată decât funcția motorie grosieră. Dintre aceşti bolnavi, conform clasificării GMFCS, 19 (51,35\%) puteau merge independent, 
TABELUL 3. Clasificarea copiilor cu paralizie cerebrală în funcție de sistemul de clasificare Gross Motor Function Classification System şi Manual Ability Classification System

\begin{tabular}{|c|c|c|c|c|c|c|}
\hline \multirow{2}{*}{ GMFCS } & \multirow{2}{*}{ Nr. copii } & \multicolumn{5}{|c|}{ MACS } \\
\hline & & Grad I & Grad II & Grad III & Grad IV & Grad V \\
\hline $\begin{array}{l}\text { Monoplegie } \\
\text { Grad I }\end{array}$ & 4 & 4 (100\%) & - & - & - & - \\
\hline $\begin{array}{l}\text { Hemiplegie spastică } \\
\text { Grad I } \\
\text { Grad II } \\
\text { Grad III } \\
\text { Grad IV } \\
\text { Grad V }\end{array}$ & $\begin{array}{c}37 \\
19 \\
17 \\
1 \\
- \\
-\end{array}$ & $\begin{array}{c}9(24,32 \%) \\
- \\
- \\
- \\
-\end{array}$ & $\begin{array}{c}10(27,03 \%) \\
11(29,73 \%) \\
- \\
- \\
-\end{array}$ & $\begin{array}{c}- \\
6(16,22 \%) \\
- \\
- \\
-\end{array}$ & $\begin{array}{c}- \\
- \\
1(2,70 \%) \\
- \\
-\end{array}$ & $\begin{array}{l}- \\
- \\
- \\
- \\
-\end{array}$ \\
\hline $\begin{array}{l}\text { Diplegie spastică } \\
\text { Grad I } \\
\text { Grad II } \\
\text { Grad III } \\
\text { Grad IV } \\
\text { Grad V }\end{array}$ & $\begin{array}{l}39 \\
11 \\
12 \\
7 \\
9 \\
-\end{array}$ & $\begin{array}{c}8(20,53 \%) \\
7(17,95 \%) \\
3(7,69 \%) \\
1(2,56 \%) \\
-\end{array}$ & $\begin{array}{c}2(5,13 \%) \\
3(3,79 \%) \\
2(5,13 \%) \\
2(5,13 \%) \\
-\end{array}$ & $\begin{array}{c}1(2,56 \%) \\
2(5,13 \%) \\
1(2,56 \%) \\
3(7,69 \%) \\
-\end{array}$ & $\begin{array}{c}- \\
- \\
1(2,56 \%) \\
3(7,69 \%) \\
-\end{array}$ & $\begin{array}{l}- \\
- \\
- \\
-\end{array}$ \\
\hline $\begin{array}{l}\text { Tetraplegie spastică } \\
\text { Grad I } \\
\text { Grad II } \\
\text { Grad III } \\
\text { Grad IV } \\
\text { Grad V }\end{array}$ & $\begin{array}{c}34 \\
- \\
- \\
- \\
2 \\
32 \\
\end{array}$ & $\begin{array}{l}- \\
- \\
- \\
- \\
-\end{array}$ & $\begin{array}{l}- \\
- \\
- \\
- \\
-\end{array}$ & $\begin{array}{l}- \\
- \\
- \\
- \\
-\end{array}$ & $\begin{array}{c}- \\
- \\
- \\
1(2,94 \%) \\
1(2,94 \%)\end{array}$ & $\begin{array}{c}- \\
- \\
- \\
1(2,94 \%) \\
31(91,18 \%)\end{array}$ \\
\hline $\begin{array}{l}\text { PC diskinetică } \\
\text { Grad I } \\
\text { Grad II } \\
\text { Grad III } \\
\text { Grad IV } \\
\text { Grad V } \\
\end{array}$ & $\begin{array}{l}8 \\
1 \\
1 \\
1 \\
3 \\
2 \\
\end{array}$ & $\begin{array}{c}1(12,5 \%) \\
- \\
- \\
- \\
- \\
\end{array}$ & $\begin{array}{c}- \\
1(12,5 \%) \\
- \\
- \\
- \\
\end{array}$ & $\begin{array}{c}- \\
- \\
1(12,5 \%) \\
- \\
- \\
\end{array}$ & $\begin{array}{c}- \\
- \\
- \\
2(25 \%) \\
1(12,5 \%) \\
\end{array}$ & $\begin{array}{c}- \\
- \\
- \\
1(12,5 \%) \\
1(12,5 \%) \\
\end{array}$ \\
\hline $\begin{array}{l}\text { PC ataxică } \\
\text { Grad I } \\
\text { Grad II } \\
\text { Grad III } \\
\text { Grad IV } \\
\text { Grad V }\end{array}$ & $\begin{array}{l}5 \\
3 \\
1 \\
- \\
1 \\
-\end{array}$ & $\begin{array}{c}2(40 \%) \\
1(20 \%) \\
- \\
- \\
-\end{array}$ & $\begin{array}{c}1(20 \%) \\
- \\
- \\
- \\
-\end{array}$ & $\begin{array}{l}- \\
- \\
- \\
- \\
-\end{array}$ & $\begin{array}{c}- \\
- \\
- \\
1(20 \%) \\
-\end{array}$ & $\begin{array}{l}- \\
- \\
- \\
- \\
-\end{array}$ \\
\hline $\begin{array}{l}\text { PC mixtă } \\
\text { Grad I } \\
\text { Grad II } \\
\text { Grad III } \\
\text { Grad IV } \\
\text { Grad V }\end{array}$ & $\begin{array}{l}2 \\
- \\
- \\
- \\
1 \\
1\end{array}$ & $\begin{array}{l}- \\
- \\
- \\
- \\
-\end{array}$ & $\begin{array}{l}- \\
- \\
- \\
- \\
-\end{array}$ & $\begin{array}{l}- \\
- \\
- \\
- \\
-\end{array}$ & $\begin{array}{c}- \\
- \\
- \\
1(50 \%) \\
1(50 \%)\end{array}$ & $\begin{array}{l}- \\
- \\
- \\
- \\
-\end{array}$ \\
\hline
\end{tabular}

GMFCS = Gross Motor Function Classification System, MACS = Manual Ability Classification System

fără restricții, atât în mediul exterior, cât şi în interior, fiind incluşi în GMFCS grad I, iar 9 (24,32\%) dintre aceştia puteau manipula cu uşurință obiectele, fiind încadrați în MACS I. Şapte $(18,92 \%)$ pacienți cu PC spastică unilaterală aveau nevoie de ajutor în mânuirea obiectelor (MACS III+IV). În grupul copiilor cu PC spastică bilaterală atât funcția motorie grosieră, cât şi dexteritatea manuală au variat mult de la o formă la alta. Astfel, s-a observat că la pacienții cu diplegie spastică funcția motorie grosieră a fost mult mai afectată decât capacitatea copiilor de a mânui diferite obiecte. De exemplu, dintre cei 9 bolnavi cu diplegie spastică care nu se puteau deplasa, încadrați în GMFCS IV, 5 (55,55\%) puteau manipula fără ajutor obiectele, fiind incluşi în MACS grad I sau II. Toți cei 34 de copii cu tetraplegie spastică nu aveau capacitate de ambulație (GMFCS IV+V), iar 32 dintre aceştia nu-şi utilizau membrele superioare, prezentând abilităţi limitate chiar în realizarea acțiunilor simple (MACS V). La pacienții cu PC diskinetică s-a remarcat o mai mare corespondență între gradele celor două clasificări. Astfel, dintre aceşti copii, $62,5 \%$ au prezentat limitarea mobilității globale (GMFCS IV+V), având şi abilitățile manuale limitate (MACS IV+V). În studiul nostru, copiii cu PC ataxică şi cei cu formă mixtă de $\mathrm{PC}$ au reprezentat un grup mic de pacienți. Majoritatea bolnavilor cu PC ataxică au avut funcția motorie bună, 4 (80\%) fiind încadrați în gradul I/II atât în clasificarea GMFCS, cât şi MACS. Cei 
doi copii cu forme mixte de PC aveau funcția motorie sever afectată, fiind incluşi în GMFCS grad IV/V şi MACS IV.

Toate aceste date sunt asemănătoare cu cele raportate în literatură şi susţin concluzia lui Menkes (2006) (1) care aprecia că atât afectarea funcției motorii grosiere, cât şi a abilităților de manipulare a obiectelor sunt diferite în funcție de tipul de PC. Studiind relația dintre topografia şi gradul deficitului motor, Caram (2006) (7) a observat că majoritatea copiilor cu hemiplegie spastică se încadrează în gradul I GMFCS, remarcând că deficitul motor al pacienților hemiplegici este în general de grad I, II sau III. Numeroşi autori au remarcat că pacienții cu diplegie spastică se încadrează în general în primele nivele ale clasificării GMFCS. De exemplu, Pfeifer (2009) (8) nu a încadrat nici un pacient cu diplegie în gradul $\mathrm{V}$, aceleaşi rezultate regăsindu-se şi în studiul lui Caram (2006) (7) care a inclus majoritatea copiilor cu diplegie în special în primele trei grade ale clasificării GMFCS şi numai 5\% în GMFCS tip IV. Pacienții cu tetraplegie spastică prezintă, în general, forme severe de PC. Beckung (2008) (9) i-a încadrat pe toții copiii cu tetraplegie spastică în gradul V GMFCS, clasificarea celor cu PC diskinetică a cuprins cazuri de la gradul I la V, iar majoritatea celor cu forme ataxice de PC au fost incluşi în gradul III. Rezultate asemănătoare declară şi Himmelmann (2005) (10) în studiul căruia pacienții cu tetraplegie s-au încadrat la nivelul IV şi $\mathrm{V}$, iar majoritatea celor cu diskinezie la nivelul IV şi V. Caram (2006) (7) a raportat că cei mai mulţi copii cu tetraplegie urmăriți aveau forme grave de PC (grad IV, V GMFCS), cei cu diskinezie erau încadrați la nivelul II, III sau IV, iar cei cu PC ataxică erau clasificați în primele trei grupe ale Gross Motor Function Classification System.

\section{CONCLUZII}

La copiii cu PC funcția motorie grosieră şi abilitatea manuală nu sunt echivalente. Corelația dintre funcția motorie grosieră şi abilitățile manuale depind de tipul de paralizie cerebrală. La pacienții diagnosticați cu paralizie cerebrală diskinetică, ataxică şi mixtă s-a remarcat o mai mare corespondență între gradele celor două clasificări. 